\title{
Investigation on Microstructure of Heat Treated High Manganese Austenitic Cast Iron
}

\author{
A.K. Muzafar ${ }^{1, *}, M . M$. Rashidi $^{1}, I$. Mahadzir $^{1}$, and Z. Shayfull ${ }^{2}$ \\ ${ }^{1}$ Faculty of Mechanical Engineering, Universiti Malaysia Pahang, 26600 Pekan, Pahang, Malaysia. \\ ${ }^{2}$ School of manufacturing Engineering, Universiti Malaysia Perlis, Kampus Tetap Pauh Putra, 02600 \\ Arau, Perlis Malaysia.
}

\begin{abstract}
The effect of manganese addition and annealing heat treatment on microstructure of austenitic cast irons with high manganese content (Mn-Ni-resist) were investigated. The complex relationship between the development of the solidification microstructures and buildup of microsegregation in Mn-Ni-resist was obtained by using microstructure analysis and EDS analysis. The annealing heat treatment was applied at $700^{\circ} \mathrm{C}$ up to $1000^{\circ} \mathrm{C}$ to investigate the effect of the annealing temperature on the microstructure. This experiment describes the characterization of microsegregation in Mn-Ni-reist was made by means of point counting microanalysis along the microstructure. With this method, the differences of silicon, manganese and nickel distribution in alloys solidified in the microstructure were clearly evidenced. The results show microstructure consists of flake graphite embedded in austenitic matrix and carbides. There is segregation of elements in the Late To Freeze (LTF) region after solidification from melting. Manganese positively with high concentration detected in the LTF region. As for heat treatment, higher annealing temperature on the Mn-Ni-resist was reduced carbide formation. The higher annealing temperature shows carbide transformed into a smaller size and disperses through the austenitic matrix structure. The size of carbide decreased with increasing annealing temperature as observed in the microstructure.
\end{abstract}

\section{Introduction}

Austenitic cast irons also known as Ni-resist are an important casting materials and their use is justified by the specialist of mechanical properties which can be achieved, associated with their outstanding abilities on wistanding the effects of corrosion [1], heat and wear. These materials have been used for more than 50 years, dating back to early of 1930 [2]. As the nickel content varying from 13 to $37 \mathrm{wt} \%$ as one of the main element, it is the most widely utilized materials in corrosive environments, due to its excellent resistance to corrosion [3-6].

Austenitic cast irons microstructure containing high composition of austenitic matrix. This matrix appears contributed by the influence of nickel contained in the composition that acts as austenite matrix promoter. Nickel forms a continuous series of solid solutions

\footnotetext{
* Corresponding author: mrashidi@ump.edu.my
} 
with iron and has an almost unlimited solubility in austenite. It will be in austenitic matrix when high temperature and also at room temperature which make it successfully avoid matrix volume changes. This phenomenon occurs due to the volume changes which occur because of matrix phase changes between ferrite and austenite. Ni-resist able to stay consistence in austenitic matrix at all temperatures and have avoided this type of transformation [7]. This can be achieved by suitable addition of alloying elements, the time-temperature-transformation ( $\mathrm{T}-\mathrm{T}-\mathrm{T})$ curve is generally pushed to the right, make solidification curve at room temperature possible to miss the 'nose' of the T-T-T curve [1, $8,9]$. Nickel broadens the temperature range in which austenite exists and makes the austenitic matrix stable at room and lower temperatures [10]. The austenite matrix in these alloys is a metallic phase with an FCC lattice, consisting of a solid solution based on iron which all the alloying elements enter.

Although, numerous data have been published on the advantages of the Ni-resist it has a major drawback on the production cost. The high price is contributed by the nickel element cost [11]. Some efforts have been made to reduce nickel content in Ni-resist iron. Recently, evidence discovered that production of austenitic ductile cast iron having wholly austenitic matrix only by using $13.5 \% \mathrm{Ni}$ for ductile form graphite [12]. This condition suppose only applied for ASTM A436 rather than ASTM A439. On the other hand, there are several investigation purposes the use of other element as replacement for nickel such as manganese and copper. They have been the object of recent studies [13-16]. Furthermore, it is also believed that manganese is better austenite promoter than copper [15].

Manganese seem to be most promising alternative to be used as it also austenitic promoter despite manganese also suspected to interrupt with the nodularisation during solidification [17], acts as sulphur controller [18] and also well known as carbide promoter [19-21]. Although some of the nickel in these alloys can be replaced by manganese, the structure will still remain austenitic matrix. The concentrations of this element in the austenite usually differ from the average concentration in the cast iron. This is due to the limited solubility of the manganese in the liquid or solid solution which is partially soluble in it and furthermore encourages the formation of carbide. The existence of carbide is very undesirable element in producing iron which limits the possibility of their being added to austenitic cast iron but demanded when related for wear ability purpose. Manganese segregates severely in inter graphite area and be in last to freeze (LTF) region [3, 7, 21, 22]. This region is enriched with positive segregation elements such as $\mathrm{Mn}$ and $\mathrm{Cr}$ [23].

The production of austenitic cast iron with high manganese content is limited by several restrictions. As for all cast irons, the Mn-Ni-resist microstructure is affected by the manganese content and cooling rate during solidification. Larger manganese content promotes the precipitation of eutectic carbide throughout austenite matrix and expected to reduce martensite start line (Ms) temperature as reported in previous report [24]. The presence of carbide in the matrix microstructure is predicted strongly detrimental to $\mathrm{Mn}-\mathrm{Ni}$ resist mechanical properties and processing.

There are two different approaches can be used to obtain carbide free iron. The first approach would be to avoid carbide precipitation during solidification. This can be achieved by maximizing the efficiency of inoculation. Good inoculation technique managed to reduce carbide precipitation during solidification and improves its mechanical properties. The second approach would be to eliminate the carbide precipitated during solidification by means of a dissolution heat treatment.

Now attention turned to improvement associates with the application of heat treatment. It is believed that annealing able to minimize the formation of excessive carbide in microstructure cause by manganese. This information based on previous study [25]. Annealing process is a heat treatment which consists combination of operation for the purpose of obtaining certain desirable conditions or properties. Through this refining 
process will produce a mechanical structure or properties that are superior in term strength and toughness.

This study attempts to combine manganese and reduced nickel as an austenitic promoter in Ni-resist and at the same time use annealing heat treatment to reduce side effect of the manganese on the microstructure. This was aimed to investigate the effect of manganese on flake graphite of Mn-Ni-resist and annealing temperature on the microstructure of $\mathrm{Mn}-\mathrm{Ni}$ resist. The annealing temperature varies from $700^{\circ} \mathrm{C}$ up to $1000^{\circ} \mathrm{C}$. The result also will show optimum annealing temperature required to alter the microstructure and mechanical properties. Analysis was concentrated on evaluating the effect of temperature on the graphite, carbide of the modified austenitic cast iron.

\section{Experimental procedure}

\subsection{Material preparation}

The studied alloy was prepared in a $100 \mathrm{~kg}$-capacity frequency induction furnace. Initial charge materials were pig iron, pure nickel, steel scrap, Ferro manganese and austenitic iron returns. Then the materials heated until molten state. Alloying elements such as 99.0 $\mathrm{wt} \%$ pure nickel and fe- $45.0 \mathrm{wt} \% \mathrm{Mn}$ were added to the molten alloy so as to increase and control Ni and Mn percentage content respectively. The mould was made by using Y block shaped pattern with minimum thickness of $30 \mathrm{~mm}$ was prepared by using a pattern as in Figaccording to ASTM standard for austenitic cast iron [26, 27] in the green sand mould. Inoculation process with $0.5 \mathrm{wt} \% \mathrm{Fe}-\mathrm{Si}$ was introduced to melt by using late inoculation in the mould technique $[21,28,29]$.

Table 3. Chemical composition (wt. \%) of the base metal.

\begin{tabular}{|c|c|c|c|c|c|c|}
\hline Elements & $\mathbf{C}$ & $\mathbf{S i}$ & $\mathbf{N i}$ & $\mathbf{M n}$ & $\mathbf{S}$ & $\mathbf{F e}$ \\
\hline Composition wt.\% & 4.5 & 1.81 & 10.00 & 4.98 & 0.082 & balance \\
\hline
\end{tabular}

This procedure ensures that the inoculation level high and reduce magnesium fading phenomena during casting. The chemical composition of casting product was shown in Table 6. 

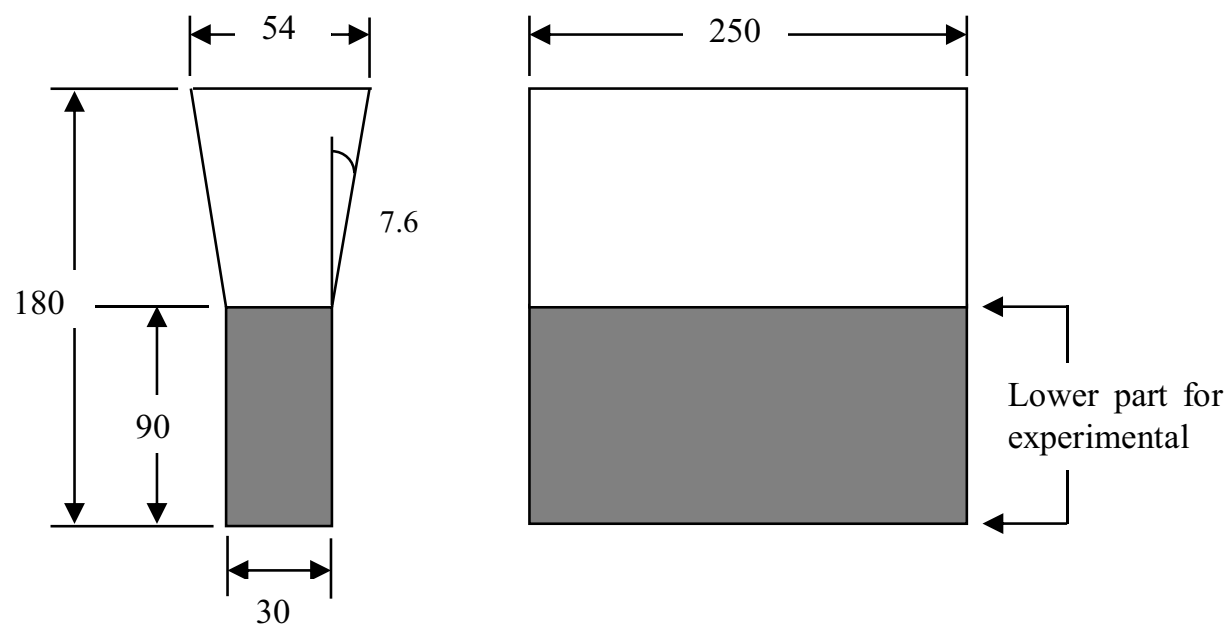

Fig. 1. Dimensions of the Y-block castings used in this experiment. Test specimens cut and machined from the lower part of the Y-block (dimensions in $\mathrm{mm}$ ).

\subsection{Heat treatment process}

The heat treatment schedule outlined in Table was carried out. All dog bone samples then were placed in a box-type resistance furnace heated according to its annealing temperature for annealing and $927^{\circ} \mathrm{C}$ for quenching. The holding time is 3 hours was counted when it reached the desired temperature. Austenitizing time less than 2 hour was not selected because the complete transformation of the as-cast structure into austenite required at least 2 hours [30]. Annealing process Annealing was held at $700^{\circ} \mathrm{C}, 800^{\circ} \mathrm{C}, 900^{\circ} \mathrm{C}$ and $1000^{\circ} \mathrm{C}$ for $3.0 \mathrm{~h}$. Then the samples cooled down to room temperature by furnace cooling respectively. For the purpose of easy analysis, as shown in Table, every heat treatment process was named according to its annealing temperature and heat treatment condition.

Due to slight oxidation of the surface of cast iron, there is every possibility of scale formation on this surface during transfer of the samples to the oil tank or cooling to room temperature and making the hardness and tensile value vary. Moreover, the specimen will not also be gripped properly in the machine. The specimens were polished to remove the scales from the surface to avoid these difficulties.

\subsection{Microstructure analysis}

The metallographic analysis of the specimens was carried out in the round shaped specimen obtained from the broken halves of the tensile specimen. Metallographic samples were sectioned, ground and polished with 1 to $6 \mu \mathrm{m}$ grade diamond paste, rinsed in distilled water and degreased with ethanol. The etch solution of $3 \%$ Nital was used for investigation of microstructure of samples. The microstructure was examined using optical microscope $(\mathrm{OM})$ and scanning electron microscope (SEM) equipped with energy dispersive X-ray spectrometry (EDS). The carbide area fraction (CAF) was obtained by image analysis using images analyzer ImageJ [31]. The retained austenite content of the specimens was measured through X-ray diffraction by a diffractometer. 
Table 4. Chemical composition of raw material.

\begin{tabular}{|c|c|c|c|c|c|c|c|c|c|c|c|}
\hline \multirow{2}{*}{ Material } & \multicolumn{10}{|c|}{ Elements (wt. \%) } \\
\cline { 2 - 13 } & $\mathbf{C}$ & $\mathbf{S i}$ & $\mathbf{M n}$ & $\mathbf{P}$ & $\mathbf{S}$ & $\mathbf{M g}$ & $\mathbf{N i}$ & $\mathbf{C a}$ & $\mathbf{C r}$ & $\mathbf{R . E}$ & $\mathbf{F e}$ \\
\hline Pig iron & 4.5 & 1.73 & 0.309 & 0.180 & 0.150 & 0.310 & 0.236 & - & - & - & balance \\
\hline Steel & 0.19 & 0.15 & 0.54 & 0.90 & 0.02 & - & - & - & - & - & balance \\
\hline Nickel & - & - & - & - & - & - & 99.0 & - & - & - & balance \\
\hline FeMn & - & - & 86.00 & - & - & - & - & - & - & - & - \\
\hline Inoculant & - & 70.00 & - & - & - & - & - & 2.0 & - & - & balance \\
\hline
\end{tabular}

\section{Result and discussion}

\subsection{Microstructure analysis}

Fig presents microstructure images for each heat treated sample (as-cast, $700^{\circ} \mathrm{C}, 800^{\circ} \mathrm{C}$, $900^{\circ} \mathrm{C}, 1000^{\circ} \mathrm{C}$ ) under examination at $10 \mathrm{x}$ magnifications with temperature respectively. Metallographic observation shows that all samples are in austenitic microstructure with single bright matrix and the graphite precipitated in the form of flake graphite type VII or more specific type B (rosette pattern) of flake graphite as according to ASTM 247 [32]. High nickel content has produced austenitic matrix as reported in literature [12].

Fig (a) are in as-cast condition generally, shows dark flake graphite distributed and embedded throughout in the austenite matrix. Austenitic irons must contain sufficient amount of nickel and manganese in order to promote austenitic characteristic. Literature indicates that $13.5 \mathrm{wt} \% \mathrm{Ni}$ together with presence of $5.5 \mathrm{wt} \% \mathrm{Cu}$ for standard types of austenitic gray cast iron [26]. Through this study, the minimum Ni (10wt.\%) used with addition of manganese ( $6 \mathrm{wt} . \%$ ) to assist in promoting austenite matrix which is lower than the previous study and ASTM A436. Even though the combination of higher manganese $\mathrm{wt} \%$ and less nickel wt $\%$ stabilized the austenite matrix, it is appears that those combination encourage carbide formation as reported previously [8, 14, 15].

In $\mathrm{Mn}-\mathrm{Ni}$-cast iron carbide formation was detected in area inter flake graphite region where located at grain boundary. Although, it is difficult to distinguish the boundary or frame of the iron in the microstructure, the location of carbide believed presence in grain boundary as stated by Jiyang [33] this was evidently supported by

Fig(a). As for carbide formation, this occurrences indicates segregated carbide suppress the existences of free graphite as concludes by latest investigation [21]. The formations of the carbide in this region push the graphite aside. It is making the length between graphite increases. This area is enriched with positive segregation elements such as $\mathrm{Mn}$, as shown in

Fig and

Fig. Generally, they was segregated at alloyed iron grain boundary and identifies as the last to freeze (LTF) region. During the solidification of iron melt, manganese was pushed away from the solid phase (graphite) which is first nucleate and solidifies. Manganese become the last element solidifies after the nucleation of graphite. It has been grouped and segregated away from the graphite. Besides, carbides in cast iron are also obviously situated between austenite dendrites, see

Fig. 

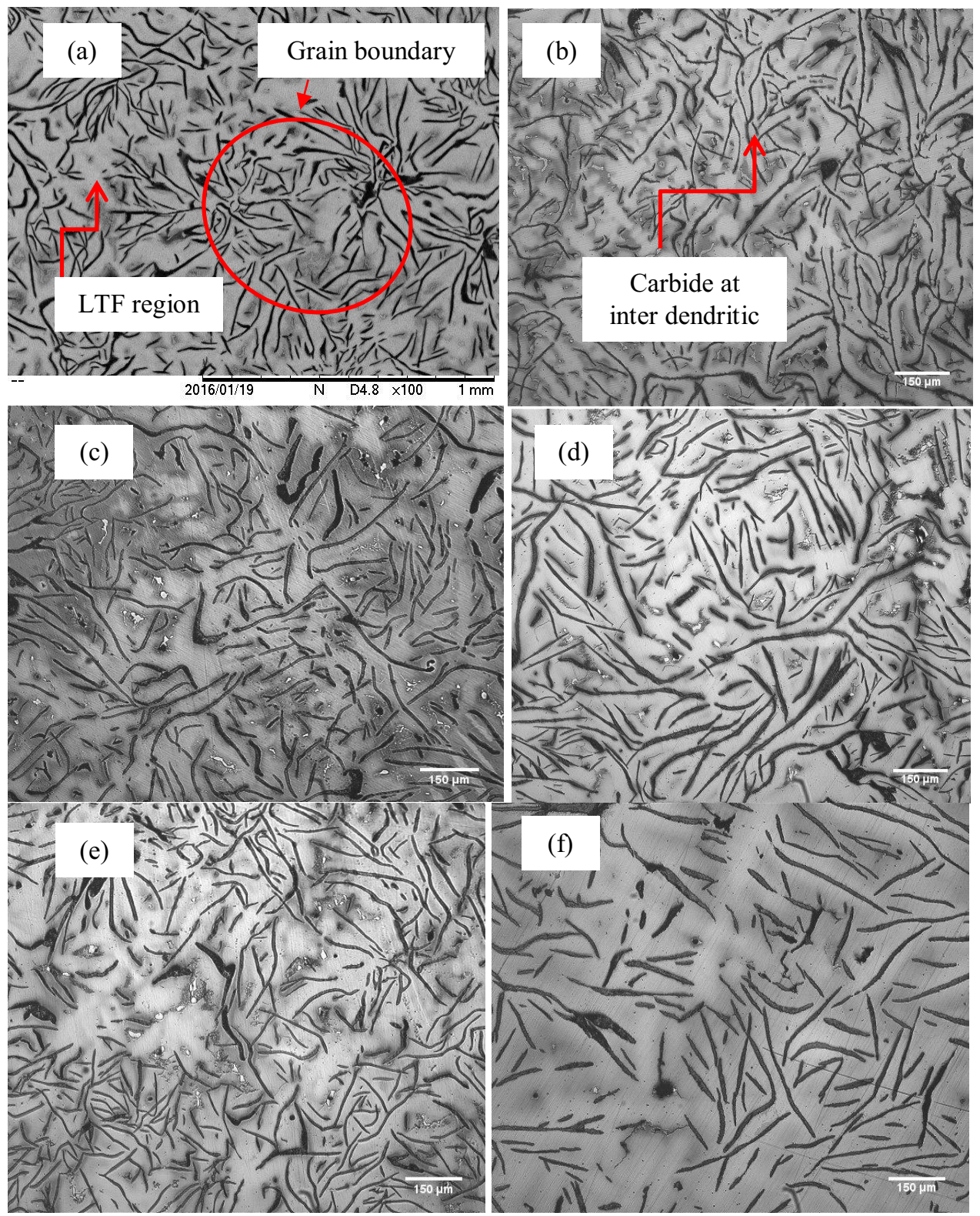

Fig. 2. Microstructure of the modified M-N-resist under 10X magnification: (a) as-cast $100 \mathrm{X}$ magnification (b) As- cast condition, (c) Annealing $700^{\circ} \mathrm{C}$, (d) Annealing $800^{\circ} \mathrm{C}$ (e) Annealing $900^{\circ} \mathrm{C}$ (f) Annealing $1000^{\circ} \mathrm{C}$.

Fig (a) to (e) were exemplifier the sequence of carbide formation throughout the microstructure. Carbide was observed dissolves progressively. The rate of carbide dissolution was slow at low temperature but very fast at high temperature. For all cases the dissolution was successfully decrease carbide formation depending on the holding temperature compared to as-cast condition. It was found that the microstructure of the original cast iron with a structure of carbide is higher than that of cast iron with the same chemical composition with a structure of carbide obtained by heat treatment. Increasing 
annealing temperature shows decreasing pattern of the carbide appearance in the microstructure. As the quantitative observation as recorded in

Table, area fraction of carbide decreasing. As-cast iron with $0.54 \%$ carbide decreases to $0.51 \%$ for sample $700^{\circ} \mathrm{C}, 0.49 \%$ for sample $800^{\circ} \mathrm{C}$ and $0.32 \%$ for sample $900^{\circ} \mathrm{C}$. Surprisingly, a very fast rate of dissolution of carbides was observed in the sample $1000^{\circ} \mathrm{C}$ as compared to the carbide dissolution of sample $900^{\circ} \mathrm{C}$. Very high drop reading showed from $0.32 \%$ to $\quad 0.06 \%$ may result from the contribution of near to transition region line A1 which is in the partial melting region. This lower A1 effect by the presences of manganese as austenite stabilizer also lowered the temperatures A1 [24] and believed to drop near to $1000^{\circ} \mathrm{C}$. This discovery supported the previous investigation by Ahmadabadi and Feghahati [34] which reported that a heat treatment involving an austenitising at temperature partial melting was sufficient and higher rate to reduce free carbides present in samples.

Table 3. Quantitative microstructure analysis.

\begin{tabular}{|c|c|c|c|c|}
\hline \multirow{2}{*}{$\begin{array}{c}\text { Condition / Sample } \\
\text { name }\end{array}$} & \multicolumn{4}{|c|}{ Carbide } \\
\cline { 2 - 5 } & $\begin{array}{c}\text { Area } \\
\text { average } \\
\left(\boldsymbol{\mu \mathbf { m } ^ { 2 } )}\right.\end{array}$ & $\begin{array}{c}\text { Percentage } \\
\mathbf{( \% )}\end{array}$ & $\begin{array}{c}\text { Total carbide } \\
\text { area }\left(\boldsymbol{\mu \mathbf { m } ^ { 2 } )}\right.\end{array}$ & $\begin{array}{c}\text { Number of } \\
\text { carbide }\end{array}$ \\
\hline As-Cast & 55.34 & 0.54 & 6918.38 & 125 \\
\hline $700^{\circ} \mathrm{C}$ & 45.40 & 0.51 & 6583.50 & 145 \\
\hline $800^{\circ} \mathrm{C}$ & 38.73 & 0.49 & 6312.24 & 163 \\
\hline $900^{\circ} \mathrm{C}$ & 34.92 & 0.32 & 4155.21 & 119 \\
\hline $1000^{\circ} \mathrm{C}$ & 24.56 & 0.06 & 835.13 & 34 \\
\hline
\end{tabular}

\section{As shown in}

Fig the shape and distribution of the carbide particles are irregular. The carbide disperses through the matrix as the temperature increases forms. Increasing the holding temperature of the annealing decreases the carbide size prior to solidification and as a sequence, the tendency of the carbide to formed dispersed carbide is high. Carbide dispersed but still grouping at the LTF region and believed to slowly dissolve into austenite as the temperature of annealing increase. This is evidently shown in Table, a result of the number and small size carbide grouping in the inter graphite region. The growth of small dispersed carbide becomes the dominant pattern for entire matrix.

\subsection{SEM analysis}

The concentration of the elements is unevenly distributed in the microstructure. This phenomenon was known as micro segregation.

Fig and Table 5 shows the location of the probe and element of silicon, manganese and nickel in the region between graphite. It shows increasing reading pattern for manganese at a certain point. Overall, the highest reading is at point $\mathrm{C}$ and point $\mathrm{D}$ as evident of micro segregation of manganese at the LTF region. When this element is too much enriched in the $\mathrm{LTF}$, thus expectedly leading to formation of carbide $\left(\mathrm{Mn}_{23} \mathrm{C}_{6}\right)$ as be evidenced by Rashidi and Hasbullah [7] and also predicted earlier by Fallon [35] and Morrison [36]. Furthermore the detriment effect will exceed positive effect. Point B and E exhibit decreasing pattern of reading as the probe located near to graphite. Nickel reading shows two increasing pattern and peak reading at point $\mathrm{B}$ and $\mathrm{E}$. This pattern indicates that nickel is positive at region 
between LTF and graphite. In LTF region nickel shows a negative segregation reading contrast to manganese. As expectedly, same graph pattern happened to silicon for what happen to nickel which is positive segregate at region between LTF and graphite.

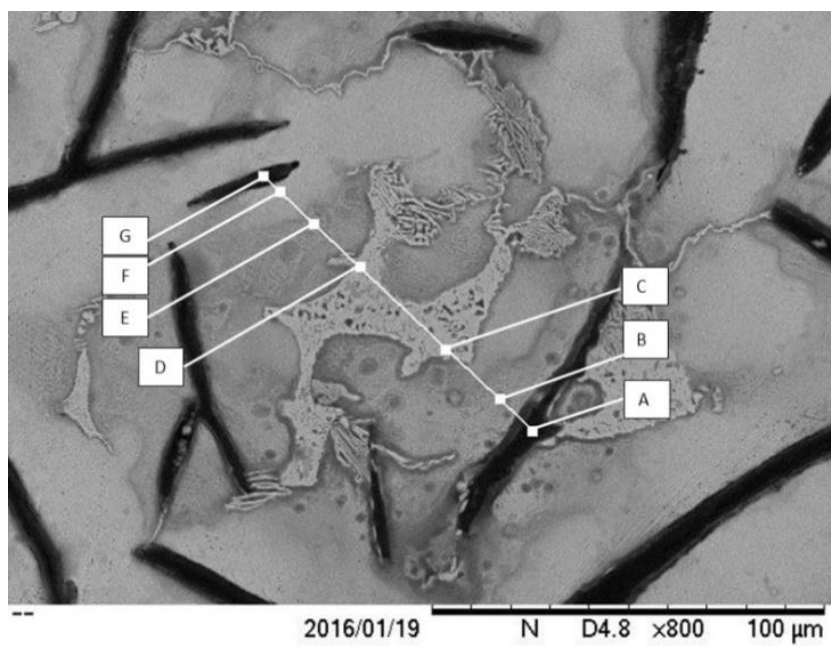

Fig. 3. Microstructure of high manganese austenitic cast iron with carbide presence

Table 5. Element constituent in the microstructure.

\begin{tabular}{|c|c|c|c|c|c|c|c|}
\hline \multirow{2}{*}{ Elements } & \multicolumn{7}{|c|}{ Electron probe location } \\
\cline { 2 - 8 } & A & B & C & D & E & F & G \\
\hline Nickel $(\mathrm{Ni})$ & 5.094 & 6.466 & 3.269 & 6.594 & 7.287 & 3.470 & 0.231 \\
\hline Manganese $(\mathrm{Mn})$ & 2.728 & 6.616 & 18.007 & 12.585 & 6.138 & 6.016 & 0.428 \\
\hline Silicon $(\mathrm{Si})$ & 0.762 & 1.834 & 0.034 & 0.752 & 1.224 & 0.863 & 0.772 \\
\hline
\end{tabular}

\section{Conclusion}

Base on the above results and discussion, the following conclusions are made:

1. Formation of carbide due to element segregation of manganese in inter graphite region throughout microstructure.

2. Increasing the annealing temperature reduce more segregated carbide in the LTF region in microstructure resulting in improvement in tensile strength and lowering the hardness value.

3. Higher hardness is seen for the sample having higher carbide volume in the matrix.

4. Less precipitation of carbide, $\mathrm{Mn}_{23} \mathrm{C}_{6}$ phase observed at grain boundaries of $\mathrm{Mn}$ Ni-resist by increasing annealing temperature. There is possibility that annealing temperature minimize the segregation existence in alloyed iron. Segregation is the prime factor that influenced precipitation of carbide, $\mathrm{Mn}_{23} \mathrm{C}_{6}$ phase.

5. Fast rate of dissolution of carbides was observed in the sample $1000^{\circ} \mathrm{C}$ as compared to the carbide dissolution of sample $900^{\circ} \mathrm{C}$ due to the partial melting state which increase carbide dissolution rate. 
The authors would like to express his sincere thanks to Universiti Malaysia Pahang (UMP) and ministry of education (Malaysia) for providing laboratory facilities and financial assistance under project no. RDU 140135.

\section{References}

1. M.M. Rashidi, I.M. Hasbullah, Mater. Design, 51, 861 (2013)

2. R.J. McKay, Ind. Eng. Chem., 28, 1391 (1936)

3. F. Alabbasian, S.M.A. Boutorabi, S. Kheirandish, Mat. Sci. Eng. A, 651, 467 (2016)

4. Y.A. Alzafin, A.H.I. Mourad, M.A. Zour, O.A. Abuzeid, Eng. Fail. Anal., 16, 733 (2009)

5. D. Zeng, C. Xie, Q. Hu, K.C. Yung, Scripta. Mater., 44, 651 (2001)

6. Y.L. Yang, Z.Y. Cao, Z.S. Lian, H.X. Yu, Adv. Mat. Res., 194-196, 95 (2011)

7. M.M. Rashidi, and I.M. Hasbullah, Mat. Sci. Eng. A, 574, 226 (2013)

8. R.D. Forrest, Foundry Trade J. Int., 5, 138 (1983)

9. A.I. Yatsenko, B.F. Martsiniv, Met. Sci. Heat. Treat., 10, 890 (1968)

10. L.I. Aptekar', Y.E. Abramenko, Met. Sci. Heat. Treat., 19, 280 (1977)

11. T. Oshima, ISIJ Int., 47(3), 359 (2007)

12. N. Fatahalla, A. AbuElEzz, M. Semeida, Mat. Sci. Eng. A, 504, 81 (2009)

13. A. Janus, K. Granat, Arch. Civ. Mech. Eng., 14, 602 (2014)

14. M.M. Rashidi, I.M. Hasbullah, Z. Shayfull, Key. Eng. Mat., 594-595, 98 (2013)

15. G.J Cox, Foundryman., 81, 453 (1988)

16. M.P. Shebatinov, Y.E. Abramenko, Met. Sci. Heat. Treat., 28, 425 (1986)

17. A. Roula, G.A. Kosnikov, Mat. Lett., 62, 3796 (2008)

18. R. Gundlach, M. Meyer, L. Winardi, Int. J. Metalcasting, 9, 69 (2015)

19. K.N. Murthy, P. Sampathkumaran, S. Seetharamu, Wear, 267, 1393 (2009)

20. X. Yaer, K. Shimizu, H. Matsumoto, T. Kitsudo, T. Momono, Wear, 264, 947 (2008)

21. M.M. Rashidi, I.M. Hasbullah, Mat. Sci. Eng. A, 597, 395 (2014)

22. M.N. Ahmadabadi, E. Niyama, M. Tanino, T. Ohide, Metall. Mat. Trans. A, 25, 911 (1994)

23. A. Owhadi, J. Hedjazi, P. Davami, M. Fazli, J.M. Shabestari, Mat. Sci. Tech., 13, 813 (1997)

24. R.K. Dasgupta, D.K. Mondal, A.K. Chakarabarti, A.C. Ganguli, Int. J. Cast. Met. Res., 25, 239 (2012)

25. D.I. Stanchev, V.I. Rublev, Y.G.Sednev, A.M. Filatov, Met. Sci. Heat Treat., 18, 514 (1976)

26. ASTM A436, ASTM Int.,(2001)

27. ASTM A439, ASTM Int.,(2001)

28. T. Skaland, ELKEM ASA Res., 1 (1999)

29. M. Chisamera, I. Ripson, S. Stan, E. Stefan, G. Costache, China Found., 6, 145 (2009)

30. S.K. Putatunda, Mater. Design, 24, 435 (2003)

31. C.A. Schneider, W.S. Rasband, K.W. Eliceiri, Nat. Methods, 9, 671 (2012)

32. ASTM A247, ASTM Int.,(2001)

33. Z. Jiyang, China Found., (2009)

34. M.N. Ahmadabadi, S. Feghahati, Int. J. Cast. Met. Res., 20, 53 (2013)

35. M. Fallon, BCIRA Tech., 9315, 8 (1998) 